\title{
IT Support for the generic tactical decision making process of pricing in competitive consumer markets
}

\author{
Madan G. Singh and Nathalie Cassaigne \\ Computation Department, UMIST, Sackville St, \\ Manchester M60 1QD, UK \\ tel. 00441612003347,00441612003358 \\ fax: 00441612003346 \\ e-mail:M_Singh@mac.co.umist.ac.uk \\ N.Cassaigne@umist.ac.uk
}

\begin{abstract}
Sustainable industrial production, which is the main theme of this conference, is only possible when the firm manufactures goods which appeal to potential customers, at prices that they are prepared to pay. These prices and the resulting sales volumes should enable the firm to meet all its costs and make a profit whilst meeting its longer term strategic goals of capturing or retaining appropriate levels of market share.

In order to help firms in the consumer goods industries to survive and prosper in competitive and fast changing markets and to enable them to meet their strategic goals, it is necessary to provide them with tools that enable them to better use the tactical decision levers at their disposal. This paper focuses on the main short or medium term lever that such companies can use in order to cope with the competition and examines the information technology needs to support the use of this lever via the business process which it constitutes i.e. the Pricing Process.

In the paper we show how certain novel pricing decision support tools developed in Manchester could be used to enable the firm to take better (i.e. more profitable) pricing decisions as compared to the unaided decision making process. Examples have been provided from the petroleum and reference is given to work on other consumer markets.
\end{abstract}

\section{INTRODUCTION}

Modern consumer goods companies can manufacture their products to meet the changing needs of their market by using information technology to make their production processes extremely flexible. The main focus of this conference is to show how information technology can be or is being used for this purpose. Yet, the main driver of this need, i.e. the changing needs of the consumer and the increased competition is only addressed peripherally in this conference. In this paper, the ways of influencing the consumer in order to maintain profitable and sustainable production is the key element considered. Specifically, how to price products within their specific competitive market in order to meet the firm's strategic goals and maximize profits is the main theme of this paper.

The kinds of firms considered in this paper are firms who sell their goods directly to the consumer at prices that they chose. Thus firms who sell their goods via intermediaries (e.g. super markets) who set the final price are not considered here since in this latter case, there is often a price negotiation whereas we are primarily focusing on the situation where the vendor 
is one amongst a small number of competing vendors who sell similar products and each is able to set his own prices at which some consumers buy and others do not. Examples would be oil companies, banks, companies making over the counter pharmaceutical products etc. In the services sector, examples would include the pricing of telecommunication services, pricing of goods on the shelf in mass retailing, pricing in banking i.e., the setting of interest rates, pricing of insurance products etc.

Human beings have been pricing goods and services for thousands of years. However, virtually all pricing decision making is based on cost based or competition based approaches or some mix of the two. Computerization has merely provided spreadsheet like tools to enable costing and thus pricing to be carried out efficiently. Whilst such efficiency is desirable, it is surely more important to improve the effectiveness of such decision making. In this paper, we will focus on the use of computers to improve the effectiveness of pricing decision making in competitive markets. This will involve the processing of information and knowledge that is potentially available but not at present used for this purpose as well as the use of a learning loop which enables the decision support tools to adapt to changes taking place within the environment of the client company.

It should be emphasized that pricing in large consumer goods companies is not something which is done by one person but it is rather a process which involves the skills and judgments of a number of people coming from different departments within the company (e.g. finance for the accounting information, manufacturing to give an idea of existing stocks and state of the production cycle, marketing and sales to provide an input on the needs of the consumers etc.).The aim here is to examine the generic pricing process in consumer goods companies and provide IT tools to support it such that the supported process enables superior decisions to be made as compared to the unaided process.

Finally, it is worth noting that the pricing decision making that is addressed in this paper is not strategic pricing which is something that one might do in a planning mode in order to figure out whether it is worthwhile to develop a new product and what its functionality's should be and at what price it will be eventually sold if the product is in fact developed. Here we are dealing with tactical pricing of existing products that needs to be displayed in the market place in the immediate future.

In the rest of this paper, we start in section 2 with a description of the generic pricing process and the pricing decision making problem that is at the heart of this process. In section 3 , we provide an outline of generic tools developed in the Decision Technologies Group at UMIST to support such decisions. In section 4, we show the specialization of this tool for the petrol pricing decision making process as well as the results from controlled trials of the use of this system to demonstrate the improvement in effectiveness of such decision making through the use of this tool. In section 5, examples from other industries are cited in order to demonstrate genericity of the concepts and tools. Some conclusions are provided in section 6 .

\section{THE GENERIC PRICING DECISION MAKING PROBLEM}

The key elements for pricing decision making are[1,2]:

- Costs and how they vary with sales volume.

- Sales and how they vary with prices.

- Impact of competitor prices on the sales of the company's products.

- Interactions between the prices of certain products within the company's product

- Portfolio and sales of other products within the same portfolio (cannibalization effects).

- Strategic issues of: Price Positioning and Market Share goals

Information about costs comes from the accounting systems within the firm. However, typical accounting systems do not readily provide the expected costs for different sales levels. For this, a model is required which separates out the fixed and variable costs and then allows 
one to predict what the costs would be as the sales or other variables which affect the costs change.

.Information and knowledge about the relationships between the sales and own prices lies in principle with the sales managers and the marketeers of the company. The competitor analysis section within the marketing department typically possesses information and knowledge

about the likely impact of changes in competitor prices on the sales of the company's products.

Although most of pricing practice is based on the idea that the pricing of each product of the firm be considered independently of the other products of the firm, there is significant profit potential if we can model the inter-relationships between the products. For example, certain products within the portfolio of the company might be in very price-sensitive markets whilst others might be in less price-sensitive markets. This might allow for tradeoffs to be made between the products thus allowing for better pricing. Again the sales and marketing departments should possess the information and knowledge required to assess these relationships.

As far as the strategic aspects are concerned, two generic issues stand out i.e. price positioning and market share goals.

Price positioning is concerned with giving signals to consumers about the quality of the company's products and it typically involves ensuring that an appropriate relationship exists between the prices of the individual products of the company and those of competitors and also between the individual products of the company. Price-positioning is not changed very often since it is a part of the branding strategy of the company.

Market share goals represent the second key aspect of the company's strategy in that the overall market share of the company is a valuable commodity which is a significant component in the value of the company itself. It is a part of the "capital" of the company. Sales volume is an appropriate surrogate variable for market share.

It should be noted that there is always a tradeoff possible between profits and market share since more profits can be obtained at the expense of market share by increasing prices but in the longer term this is self defeating.

\subsection{The idealized generic pricing process}

In large or even medium sized firms, prices are not set by one person but are rather a group decision to which many actors contribute. It should be seen as one of the important business processes of the firm which typically is in dire need of re-engineering in order to improve its effectiveness.

The main reason for this need for re-engineering of the pricing process is that present day pricing processes were designed to solve the pricing decision making problem of the single decision maker for whom, as examined above, the pricing problem is far too complex to enable him or her to take all the above mentioned factors into account. The decision maker thus ignores most of the above factors and takes the pricing decision within the framework of satisfying rationality[3] by focusing only on costs or on the competition[4]. The advent of computers to support pricing decision making has merely re-confirmed the satisficing framework by providing spreadsheets for calculating cost based or competition based prices!

The pricing process is one of the key business processes in the firm since it is linked to the revenues of the firm: most other processes deal with the cost side of the firm. It's outputs are highly visible to the consumer and give significant "image" messages about the firm and signal the goals of the company to the competitors. Pricing, if done well, has the potential to significantly add value for the firm. Equally, if not done well, it can put into question the very survival of the firm.

In Figure 1 below, we shows what a generic idealized pricing process of the firm should look like in order to meet all the imperatives listed in section 2 above. It shows what information and knowledge is required for superior pricing decision making and from where within the company it comes from. 


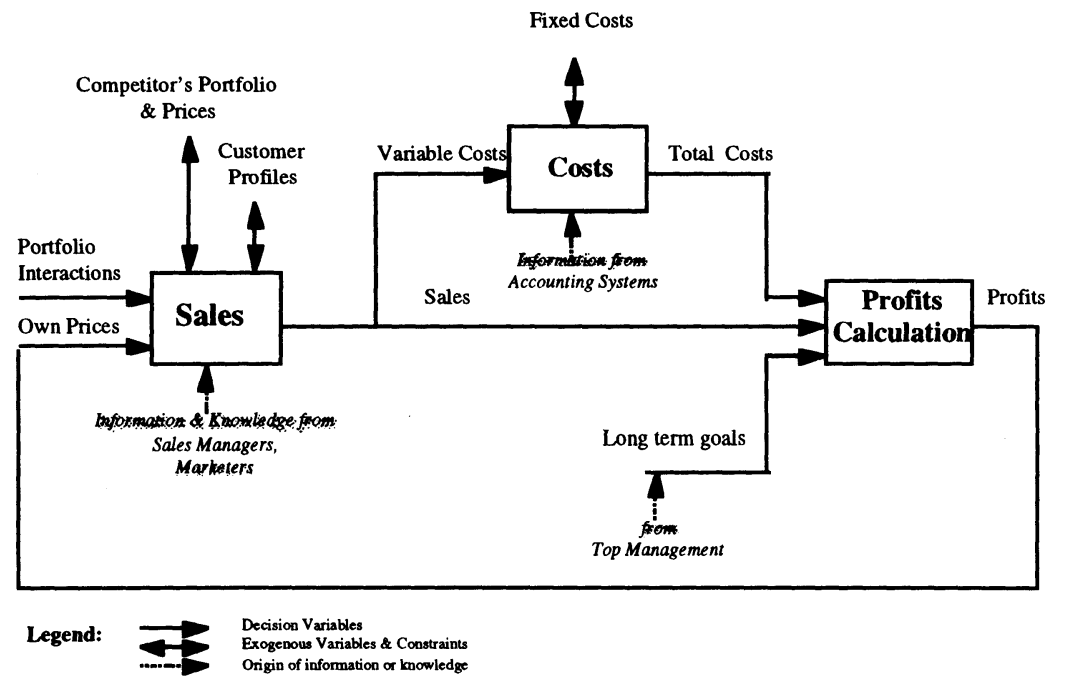

Figure 1 The generic pricing process.

Next we will examine the decision support systems developed within the decision technologies group at UMIST to support such an idealized generic pricing decision making process.

\section{DECISION SUPPORT FOR THE GENERIC IDEALIZED PRICING PROCESS: THE PRICE-STRAT SYSTEM [5]}

Price Strat is a piece of software that is sufficiently flexible to enable the user to tackle a variety of pricing issues in a coherent way. The flexible use of Price-Strat and the taking of it from one industry to another is what constitutes the Price-Strat methodology.

In order to build up a picture of demand, cost structure, company strategic objectives and competitors for any specific company in each of its markets, the Price-Strat software enables one to first construct a knowledge repository. This is built up relatively rapidly by managers defining their strategic aims, price positioning aims, their perceptions of competitors, etc. All this information is fed into the computer and used by the Price-Strat program to generate a series of 'what-if' pricing scenarios where the prices of the company's products vary as do those of different competitors. For each 'what-if' scenario, a group of the company's managers is asked to give their independent assessments of the impact on the company's sales and costs. In this way, Price-Strat is able to capture a significant element of the intuition and expert knowledge of experienced managers. The intuitive knowledge is combined with any other information available (e.g. past data and/or market research data) and this completes the knowledge repository.

The knowledge repository is then interrogated by pressing a button and within 1-2 minutes, the computer calculates the optimal prices which meet strategic constraints and maximise profits.

The user can then modify any strategic constraint and recalculate (within 1-2 minutes) the opportunity cost of shifting a strategic boundary. Equally, if a competitor makes a price move or the company's buying prices change, the new information can be fed in interactively and the resulting optimal prices for the company's portfolio of products can be calculated rapidly. 
Experience with the application of Price-Strat in different industries shows that despite the differing views of the world of the various managers (head office, regional, marketing bias, finance bias, etc.), the optimal pricing strategies are close to each other if not identical, thus demonstrating the robustness of the approach.

\subsection{Learning}

The decisions recommended by Price-Strat can be implemented and, after a short time, the real sales data can be fed in. This provides a reality check. More importantly, Price-Strat uses this new data to enrich the knowledge repository and through it, keep track of the slowly changing factors.

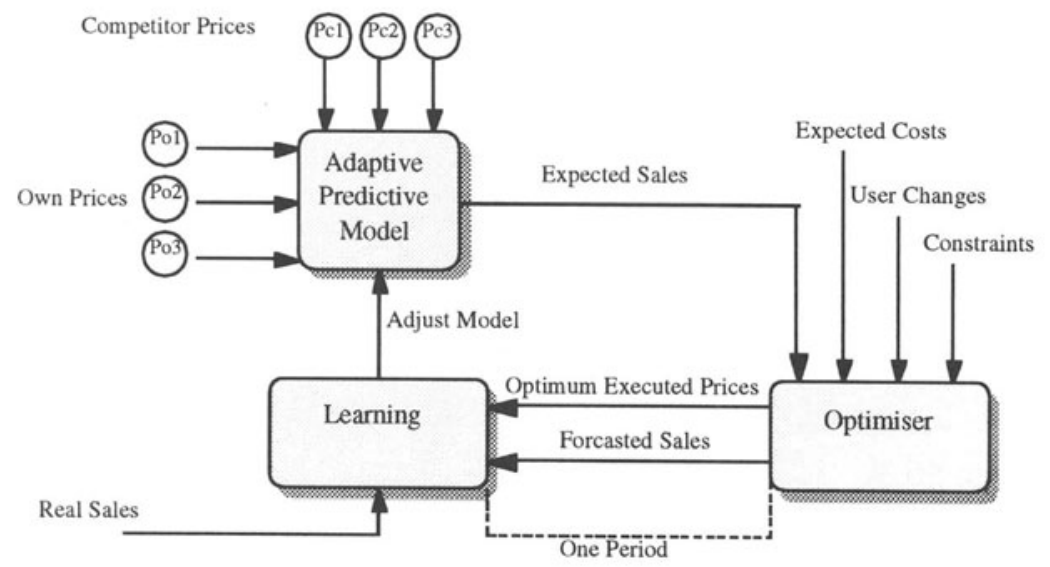

Figure 2 Price-Strat Architecture.

Figure 2 shows the generic structure of the Price-Strat Knowledge Support System for superior pricing.

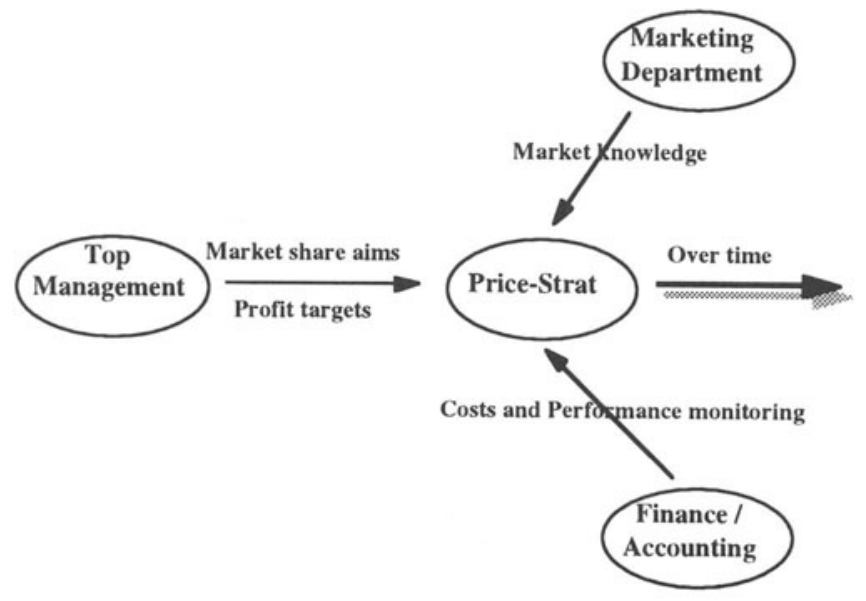

Figure 3 Price-Strat within the re-engineered pricing process. 
Figure 3 shows how Price-Strat could lie at the heart of a re-engineered ideal generic pricing process. This figure depicts Price-Strat as providing intermediation between top management (as custodians of the company's strategy), the Marketing Department (providing knowledge and information about the market) and the Finance/accounting function providing costing information and knowledge as well as performance monitoring

Next, we show the application of this approach and system for the important area of petrol pricing.

\section{KNOWLEDGE SUPPORT FOR PETROL PRICING [6]}

To quote a senior oil company executive:

"One of the most pressing issues facing fuel retailers in Europe today is the continued pressure on prices, and thus profit margins, for which intensifying competition is a significant contributory cause"

One of the most noticeable aspects of this competition is the structural change to the market caused by the penetration into the fuel retailing market of food retailing Supermarkets.

Whereas fuel retailers place considerable emphasis on brand image, station quality, product improvements and added facilities, the key to profitable retailing is increasingly becoming pricing.

The Supermarkets have established their position as low cost providers of fuel, threatening other low cost retailers who do not have the brand image. The Majors are becoming leaner, offering keener prices than before. The Mini-majors are being squeezed. The density of Supermarket outlets is increasing, intensifying the competition between them, cutting their already tight operating margins.

No section of the fuel retail market is free from this pricing pressure.

Pricing is becoming the key tactical decision to protect the Retail business. Without careful individual price management Volumes \& Profits will decline.

\subsection{The Business needs}

The most usual approach taken by fuel retailers is to keep prices in line with competitor prices. Although this does protect sales volumes, it does not enable the management to achieve profit aims. More specifically profit performance is harmed by price wars and the subsequent reaction of increasing prices (to recover profit margins) does result in the loss of sales volume.

To manage prices and to establish control over profit performance, fuel retailers aim to:-

Make available adequate up-to-date information.

- Use this information in a Pricing Process, that also uses all the skills and intuitive market knowledge available in the company, to promptly make effective price moves by grade and by outlet.

- Identify the tactics that will best achieve the strategic aims for the retail network in the competitive market place.

The Pricing Process not only needs to set effective prices, but also needs to:-

- Involve those staff with local market knowledge.

- Reassure the retail network management that the pricing image is being maintained and that the sales volume and profit performance goals will be achieved.

- Provide feedback to reassess the tactics of price, promotion, acquisition/disposal etc. that will best achieve the retail network's strategic aims. 
The Price-Strat System has been specialized for this problem and this version is called PriceNet.

\subsection{The Pricing Process using PriceNet}

PriceNet is a Price Decision Support system specifically designed for fuel retailers. PriceNet provides the key benefits of:

1. capturing and enabling the explicit use of local market knowledge on the price/sales volume models that are then constantly updated by actual performance.

2. Enabling the network management to set achievable sales volume and profit targets within an explicitly defined price positioning strategy.

3. Providing prices for each grade and each outlet that will achieve the sales volume targets more profitably.

4. Focussing management attention on those outlets that need (or would benefit from) a price move.

5. Enabling alternative pricing options to be examined; quantifying the benefits and risks of implementing each option.

6. Providing sales and profit forecasts and price positioning information that enables the network management to review tactics.

The actual management of the pricing process involves the transmittal, on a daily basis, of the prices of competing stations in the neighbourhood of each of the company's stations, by telephone to the company's main frame computer which also has in it that day's costs of the products as traded on the Rotterdam market. All this information is downloaded into PriceNet via a flatfile. PriceNet is then run by a single analyst and his manager who between them are able to control and set prices at several hundred stations.

\subsubsection{The PriceNet Price/Sales volume model}

Whilst a large number of factors influence the sales of fuel, it is only price moves that cause rapid changes in sales volumes. PriceNet models the Price/Sales volume relationship in great detail.

The PriceNet model is built by estimating for each product the elasticities for:

-the influence of its own price on sales;

-the influence of each competitor's price on sales;

-the influence of each of the other product's price on sales.

PriceNet makes an initial estimate of these relationships using local knowledge of the market supplied by the sales management, combined with historical data of the actual sales, prices and competitor prices over the recent past (if it includes at least ten significant price changes).

At the end of each week the PriceNet models are updated with actual sales performance. This learning process adjusts the elasticities and accounts for any changes in the influence of the other factors on sales volumes. 


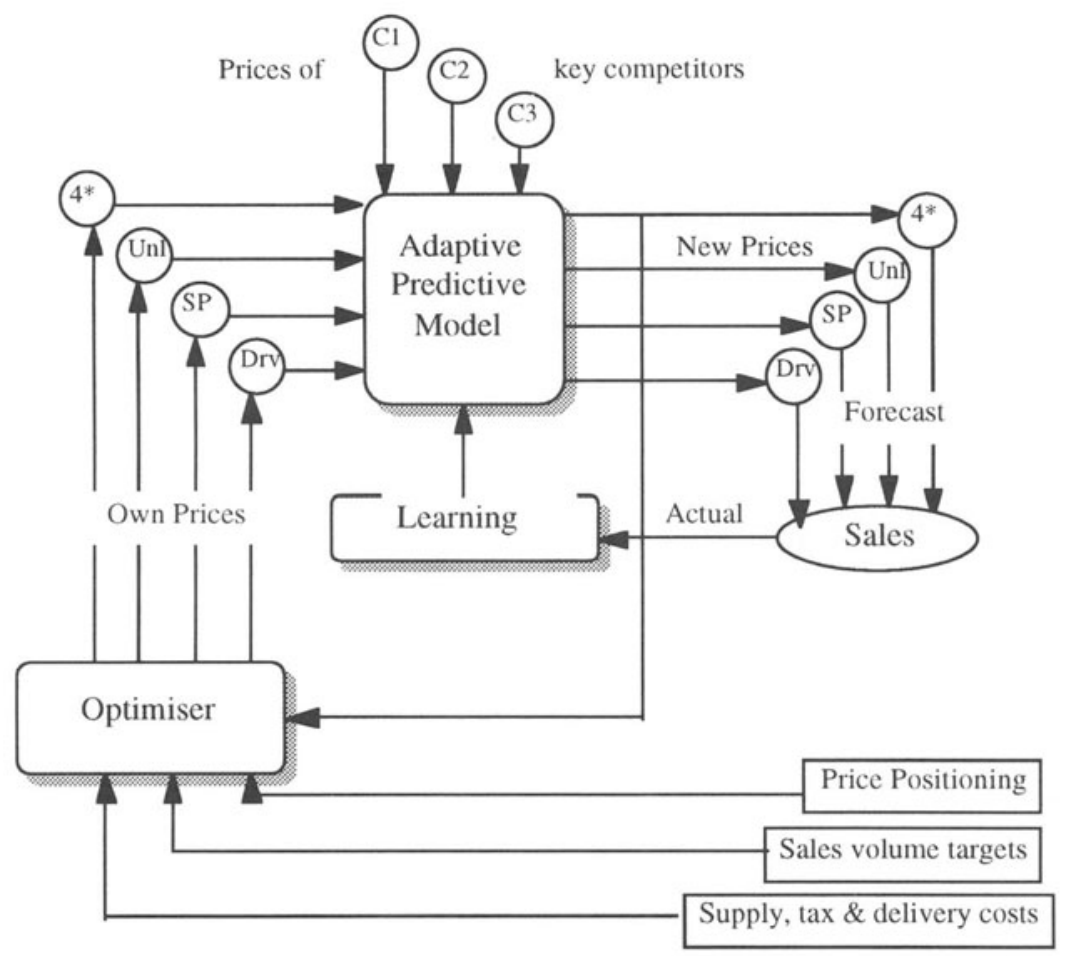

Figure 4 PriceNet site-specific price/sales model.

\subsubsection{Representing the network strategy in PriceNet}

PriceNet provides a forecast of this (coming) week's sales volume and profits, using the sitespecific models, taking competitor price moves and changes in product costs into account.

PriceNet will offer 5 options, using prices for each grade and for each station that are within the network price positioning strategy; and which give the optimum profits for five levels of sales within the achievable range. The management can select the option that best achieves their sales volume and profit aims, or revise the price positioning strategy giving more latitude for price changes.

\begin{tabular}{|l|l|l|l|l|l|}
\hline Period & Targets & $\begin{array}{l}\text { Last 6 wk's } \\
\text { actual }\end{array}$ & Last week actual & $\begin{array}{l}\text { This wk's } \\
\text { forecast } \\
\text { Current Prices }\end{array}$ & $\begin{array}{l}\text { This wk's } \\
\text { forecast } \\
\text { Proposed Prices }\end{array}$ \\
\hline Sales & 15438 & 14765 & 15081 & 14973 & 15132 \\
\hline Profits & 244 & 220 & 280 & 295 & 292 \\
\hline
\end{tabular}

The price positioning strategy is represented in PriceNet as:

- $\min / \max$ price limits for each grade

- min/max price relationships with competitors for each grade

- min/max price differentials between grades

-maximum allowable price change

-marketable prices 


\subsubsection{The Optimisation Process}

Once the network tactics have been determined for this week, PriceNet will allocate the chosen network sales volume target across the retail outlets and optimize each site-specific model to determine the prices that will achieve the sales volume target within the price positioning strategy; and yield more profit.

PriceNet resets the price changes for any outlet that yields insufficient improvement over current prices; proposing the price moves for each outlet that best achieve the chosen network tactics.

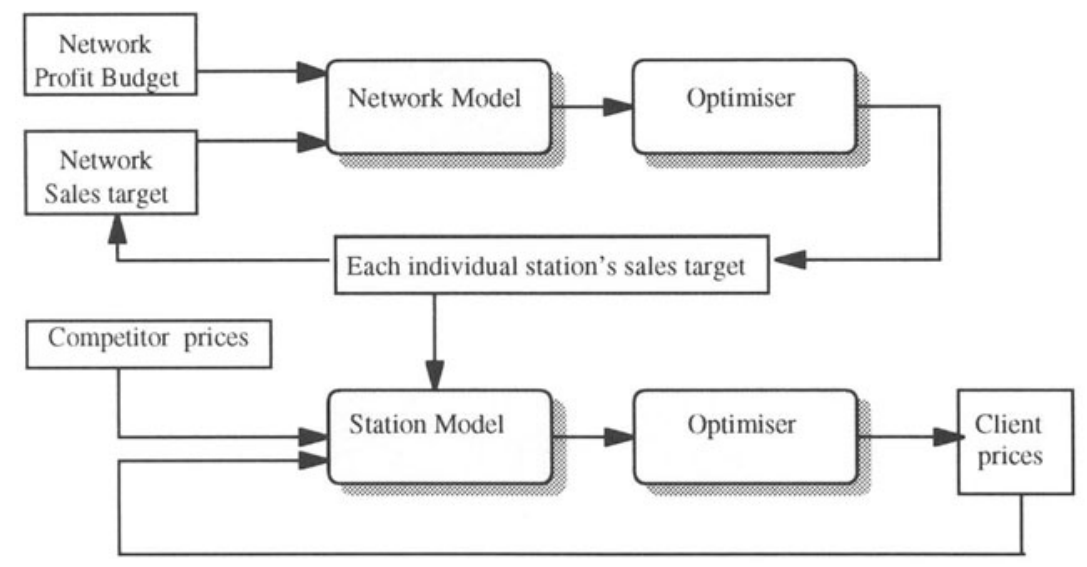

Figure 5 Group optimiser.

\subsubsection{Focusing management attention}

PriceNet provides the management with an exception report focusing attention on those outlets where a price move is proposed and flagging those outlets where competitors have made a significant price move or where the sales volume or profit performance has declined over the past six weeks.

Table 1: PriceNet exception report

\begin{tabular}{|l|c|c|c|c|c|c|c|}
\hline Station & Action & $\begin{array}{l}\text { Improve } \\
\text { profit } \\
\text { margin }\end{array}$ & $\begin{array}{l}\text { Protect sales } \\
\text { volume }\end{array}$ & $\begin{array}{l}\text { competitor or } \\
\text { price moves }\end{array}$ & $\begin{array}{l}\text { Sales } \\
\text { Volume } \\
\text { declining }\end{array}$ & $\begin{array}{l}\text { Gross profit } \\
\text { declining }\end{array}$ & $\begin{array}{l}\text { Forecast } \\
\text { note } \\
\text { correct }\end{array}$ \\
13567 & opt & $\ldots$ & 3.5 & yes & yes & $\ldots$ & $\ldots$ \\
17893 & $\ldots$ & $\ldots$ & $\ldots$ & yes & $\ldots$ & $\ldots$ & $\ldots$ \\
22678 & opt & 354 & $\ldots$ & $\ldots$ & $\ldots$ & yes & $\ldots$ \\
33654 & $\ldots$ & $\ldots$ & $\ldots$ & $\ldots$ & yes & $\ldots$ & yes \\
45632 & opt & 298 & $\ldots$ & $\ldots$ & $\ldots$ & $\ldots$ & $\ldots$ \\
56903 & opt & $\ldots$ & 2.7 & yes & $\ldots$ & $\ldots$ & $\ldots$ \\
etc. & & & & & & & $\ldots$ \\
\hline
\end{tabular}




\subsubsection{Reviewing pricing options}

PriceNet provides for each outlet a 13 week history of own and competitor prices, sales volumes and profits performance. The display enables price move patterns and sales effects to be easily identified.

The sales and profit performance of alternative pricing options for each outlet can then be reviewed using the PriceNet model. The risks of competitor price reactions to the pricing option can be assessed.

PriceNet provides an output file of the price moves made by the Pricing Process.

Table 2: price history

\begin{tabular}{|c|c|c|c|c|c|c|c|c|c|}
\hline & Grade & Propose & Current & 19 Nov & $12-\mathrm{Nov}$ & 07-Nov & $30-O c t$ & $23-O c t$ & $16-O c t$ \\
\hline $\begin{array}{l}\text { Each key } \\
\text { competitors } \\
\text { price }\end{array}$ & $\begin{array}{l}* \\
\text { Unld } \\
\text { Super } \\
\text { Diesel }\end{array}$ & & & & & & & & \\
\hline Client Prices & $\begin{array}{l}* \\
\text { Unld } \\
\text { Super } \\
\text { Diesel }\end{array}$ & & & & & & & & \\
\hline $\begin{array}{l}\text { Sales 000(s) } \\
\text { Litres }\end{array}$ & $\begin{array}{l}* \\
\text { Unld } \\
\text { Super } \\
\text { Diesel }\end{array}$ & & & & & & & & \\
\hline $\begin{array}{l}\text { Total Sales } \\
\text { Target Sales }\end{array}$ & $\begin{array}{l}* \\
\text { Unld } \\
\text { Super } \\
\text { Diesel }\end{array}$ & & & & & & & & \\
\hline \begin{tabular}{|l} 
Gross \\
Profits \\
\\
Total Profits
\end{tabular} & $\begin{array}{l}* \\
\text { Unld } \\
\text { Super } \\
\text { Diesel }\end{array}$ & & & & & & & & \\
\hline
\end{tabular}

\subsubsection{Summary network performance}

PriceNet provides a sales volume and profit forecast for each outlet and for the retail network.

PriceNet provides a comparison of client and competitor prices. Enabling the confirmation, at a glance, that the price moves are in line with the desired network tactics.

\begin{tabular}{|c|c|c|l|c|c|c|c|}
\hline \multicolumn{3}{|c|}{ Sales Volumes 000(s) Litres } & \multicolumn{4}{c|}{ Profit Margin £000(s) } \\
\hline Objective & $\begin{array}{l}\text { Last 6 } \\
\text { week's } \\
\text { actual }\end{array}$ & $\begin{array}{l}\text { Last week } \\
\text { actual }\end{array}$ & $\begin{array}{l}\text { This } \\
\text { week's } \\
\text { f/cast }\end{array}$ & Objective & $\begin{array}{l}\text { Last 6 } \\
\text { week's } \\
\text { actual }\end{array}$ & $\begin{array}{l}\text { Last } \\
\text { week's } \\
\text { actual }\end{array}$ & $\begin{array}{l}\text { This } \\
\text { week's } \\
\text { f/cast }\end{array}$ \\
\hline 15438 & 1476 & 1508 & 150 & 244 & 220 & 280 & 289 \\
\hline & 5 & 1 & 76 & & & & \\
\hline
\end{tabular}




\begin{tabular}{|c|c|c|c|c|c|c|}
\hline \multicolumn{4}{|c|}{ Client Prices } & \multicolumn{3}{c|}{ Competitor Prices } \\
\hline 6 week & Last week & This week & pence/litre & 6 week & Last week & $\begin{array}{c}\text { This } \\
\text { week }\end{array}$ \\
\hline 55.9 & 56.1 & 56.2 & $4^{*}$ & 56.1 & 56.0 & 56.0 \\
\hline 50.4 & 50.7 & 50.9 & Unld & 50.5 & 50.4 & 50.4 \\
\hline 54.5 & 55.2 & 55.4 & $\begin{array}{c}\text { Super } \\
\text { Plus }\end{array}$ & 54.8 & 54.8 & 54.8 \\
\hline 51.1 & 51.2 & 51.3 & Diesel & 50.4 & 50.3 & 50.2 \\
\hline
\end{tabular}

\subsubsection{Identifying effective tactics to achieve the strategic network aims}

The PriceNet site-specific models clarify the pricing opportunities (or lack of them) for each outlet. This feedback helps the network

-For a client in the United Kingdom, where 90 day experiments were done on six sites in different parts of the country, average net margin increased by $33 \%$ whilst volume dropped by $1 \%$ within the clients strategic price positioning aims.

-At DTW areas and Jobber terminals, improvements in profitability over the period considered was $30 \%$ and $4 \%$, respectively.

These experiments are described in detailed in [6]. They demonstrated the significant potential of Price-Strat to improve oil company profits through superior pricing.

Following on from these experiments, large scale experiments on petrol pricing were done on an oil major in the United Kingdom for a much larger number of sites over 1 year. As a result, Texaco (UK) Ltd. and Repsol UK have obtained a licence for this technology, and other oil companies are currently testing it in both Europe and North America.

\section{APPLICATIONS OF THE GENERIC SYSTEM PRICE STRAT IN OTHER INDUSTRIES}

As discussed previously, the generic PriceStrat system, which is in fact a toolkit, can be used to provide pricing decision support for the pricing process of any firm which sells directly to large number of consumers and is thus able to set its prices which consumers take or leave. in the previous section, we have seen that in the case of petrol pricing, in view of the fact that petrol prices change very often, it was worthwhile to specialise the PriceStrat toolkit into the PriceNet System for use within the Pricing Process of oil retailers. The same has been done for a number of other industries. For example, the Bank Price System [7] supports the pricing process of retail banks and helps them to set interest rates for savings and lending products.

The Tele-Price System has been designed to support the pricing process of telecommunication companies and enables such companies to set the call tariffs, line rental and hand sets.

The Retail price System has been designed to support the Category Management function in Mass Retailing.

All these systems are marketed by Knowledge Support Systems Ltd., a company set up to exploit the research of the Decision Technologies Group. 


\section{CONCLUSIONS}

In this paper we have examined the key business process of pricing in consumer industries and seen that as organised at present in virtually any company, it is well worthwhile to reengineer this process. The paper has focussed especially on the provision of IT support in general and software support in particular to enable one to improve not only the efficiency but also the effectiveness of this process. We have shown how the PriceStrat family of tools is well suited for providing this support and given examples of this from a number of consumer industries including petrol retailing.

\section{REFERENCES}

1. Nagle, T. ( 1987) The strategy and tactics of pricing. Prentice-Hall, Englewood California,

2. Singh, M.G. (1991) Knowledge support systems for smarter tactical decisions for pricing and resource allocation. IEEE Control Systems Magazine, pp. 3-7.

3. Simon, H.A. (1966) The New Sciences of Management Decisions (Harper \& Row, New York, H.A.).

4. Kotler, P (1987). "Marketing management: analysis, planning and Control" Prentice-Hall, Englewood, California,.

5. Singh, M.G. and Bennavail, J.C. (1994) "PriceStrat: a knowledge support system for decision making during price wars", IDT Vol. 19, 4, pp. 277-296.

6. Singh, M.G. (1996). Knowledge support for profitable pricing in a competitive environment". Plenary paper, 4th Intl. Conference on the Cognitive Foundations of Economics and Management", Paris, September 1995. To appear in Information and Systems Engineering, Vol. 2,3.

7. Singh, M.G. (1994). Decision Technologies for supporting the interplay between Qualitative and Quantitative aspects of Managerial Decision Making. Proc. QUARDET 93, Barcelona, 16-18 June 1993. Also Mathematics, Computers and Simulation Journal, vol. 36, pp. 103-114.

\section{BIOGRAPHIES}

\section{Madan G. Singh}

Madan G. Singh B.Sc. (Exeter), M.Sc. (Manchester), Ph.D (Cambridge), Docteur es Sciences (Toulouse), C.Eng., FIEE, Fellow of the IEEE, FBCS, is the Chairman of the Computation Department and holds the chair of Information Engineering at UMIST, (the University of Manchester Institute of Science and Technology) in Manchester, England. He has been at UMIST since 1979 when he was elected to the chair of Control Engineering at the age of 33. He was the head of the Post Graduate Department "The Control Systems Centre", from 1981 to 1983 and from 1985 to 1987. Prior to that, he had been a Fellow of St. John's College Cambridge, an Associate Professor at the University of Toulouse and a researcher of the French CNRS.

Professor Singh was the first "non-American" President of the IEEE Systems, Man and Cybernetics Society $(1994,1995)$ and won the 1993 Norbert Weiner Award "for truly 
outstanding contributions to research and scholarship in Information and Decision Technologies, Optimisation and Control and Systems Engineering". In February 1994, he was made a "Chevalier dans l'ordre des Palmes Academiques" by a decree signed by the Prime Minister of France and was graciously granted unrestricted permission by The Queen to wear the insignia of this honour. Hewas awarded the degree of Doctor of Engineering, honoris causa, by the University of Waterloo, Canada in 1996.

Professor Singh edited the 10 volume "Encyclopedia of Systems and Control" for which he received an "outstanding contribution award" from the IEEE SMC Society. Indeed, the Reviewer in the prestigious journal Automatica said that "....all in all, the systems and control encyclopedia constitutes a major milestone in the annals of systems and control and in the epistomology of technologically based decision making". The project also led to his coordinating the publication of 8 Concise Encyclopedias, each on a different subject. In addition to the encyclopedia, Professor Singh has authored or co-authored 8 books and over 170 scientific articles and edited or co-edited a further 10 books. He has also directed over 50 research or major consultancy projects yielding several million pounds of funding or fees. He is the co-editor-in-chief of the journal "Information and Systems Engineering" and is the editor of the quarterly SMC Newsletter (distributed to 5500 members worldwide). He is also a member of the editorial boards of 9 other journals and edits 3 book series. He was the co-editor-in-chief of the North Holland Journal: Information and Decision Technologies (1980-94).

He was a visiting Professor at INSEAD (France) (1980-94) and is or has been an invited or honorary Professor at: Ecole Normale Superieur de Cachan, Ecole Centrale de Lille, Theseus Institut (Sophia Antipolis), and the University of Aeronautics and Astronautics in Beijing. He is a member of the Scientific Councils of the IUSPIM (Marseille) and IUP MIAGe (Aix-en-Provence).

Professor Singh is also the Chairman of the UMIST Campus company Knowledge Support Systems Ltd. and of Control Sciences Ltd. These companies provide services related to the decision support systems and decision theoretic approaches developed by Professor Singh and his collaborators within the Decision Technologies Group at UMIST on Pricing, Advertising budget allocation, shelf space allocation in retailing etc. Through various licensing arrangements, these products are being used by corporations worldwide to enhance the quality of their decision making.

Professor Singh is a citizen of both the United Kingdom and France. He is married and has two children.

\section{Nathalie P.L. Cassaigne}

Degrees:

M.Sc., DEA "Management Sciences", DESS.

"Information Systems Engineering", University of Social Sciences and INP Toulouse

Business Experience:

Research Associate in the Computation Department at UMIST and UMIST

Consultant for various French local authorities since 1991

Research:

Information Systems and Tactical Decision Support System 